\title{
Structural Elucidation of Some Borate Glass Specimen by Employing Ultrasonic and Spectroscopic Studies
}

\author{
S. Thirumaran and N. Karthikeyan \\ Department of Physics (DDE), Annamalai University, Annamalai Nagar 608 002, India \\ Correspondence should be addressed to S. Thirumaran; thirumaran64@gmail.com
}

Received 22 September 2012; Revised 1 February 2013; Accepted 4 February 2013

Academic Editor: Joon-Hyung Lee

Copyright (C) 2013 S. Thirumaran and N. Karthikeyan. This is an open access article distributed under the Creative Commons Attribution License, which permits unrestricted use, distribution, and reproduction in any medium, provided the original work is properly cited.

Quantitative analysis has been carried out in order to obtain more information about the structure of two glass systems, namely, $\left(\mathrm{B}_{2} \mathrm{O}_{3}-\mathrm{MnO}_{2}-\mathrm{PbO}\right)$ (BML glass system) and $\left(\mathrm{B}_{2} \mathrm{O}_{3}-\mathrm{Na}_{2} \mathrm{CO}_{3}-\mathrm{P}_{2} \mathrm{O}_{5}\right)$ (BSP glass system). Their structural elucidation has been carried out by studying the ultrasonic velocities (longitudinal velocities $U_{L}$ and shear velocities $U_{S}$ ) and density of these glass samples. The present investigation has been interpreted by focusing more on elastic and mechanical properties of glass specimen through ultrasonic study and the elemental analysis study through spectroscopic studies. The scanning electron microscopic (SEM) study was also carried out with a view to throwing more light on their morphological aspects. The results are corroborated in the light of the role of borate $\left(\mathrm{B}_{2} \mathrm{O}_{3}\right)$ glasses in the formation of glassy structural network.

\section{Introduction}

The acoustical properties are particularly suitable for describing glasses as a function of composition because they give some information about both the microstructure and the dynamics of the glasses. The elastic properties are related to microscopic properties through the behavior of the network and the modifier. Attempts have been made to measure and interpret the acoustical properties of borate glasses in terms of structural changes [1-3]. Bahatti and Singh [4] discussed the composition dependence of ultrasonic velocity. The ultrasonic nondestructive testing has been found to be one of the best techniques to study the microstructure, characterization, mechanical properties, and phase changes as well as to evaluate elastic constants. One can also characterize the materials such as semiconducting glasses, superconducting glasses, glass ceramics and bioactive glasses by this nondestructive testing technique. The propagation of ultrasonic wave in solids such as glass provides valuable information regarding the solid state motion in the material. Interest in glasses has rapidly increased in recent years because of diverse applications in electronic, nuclear, solar energy and acoustooptic devices. The acoustic wave propagation in bulk glasses has been of considerable interest to understand the mechanical properties [5]. The velocity of sound is particularly suitable for characterising glasses as function of composition because it gives information about the microstructure and dynamics of glasses [6]. The study of elastic properties of the glasses has inspired many researches $[7,8]$ and significant information about the same has been obtained. The elastic moduli of glasses are influenced by the many physical parameters, which may in turn be studied by measuring the ultrasonic velocities. The dependence of ultrasonic velocity on the composition of glass indicates the various changes in the structural configuration between the network former and modifiers [9].

Glass structure is a basic issue to understand the behavior of the material. The velocity of ultrasonic waves and hence the elastic moduli are particularly suitable for characterizing glasses as a function of composition [10]. Ultrasonic investigation of solids is gaining much importance nowadays and interest in glasses has rapidly increased because of improving information technology. Elastic properties are very informative about the structure of solids and they are directly related to interatomic potentials. In recent years, attention has been focused more on glassy materials in few of their larger optical nonlinearity and high optical quality with fast response time [11]. Ultrasonic tools are very important for 
characterizing materials because they have many applications in physics, chemistry, engineering, biology, food industry, medicine, oceanography, seismology, and so forth.

Borate glass is one of the most characteristic glasses having unique superstructure (SS) of intermediate range order (IRO) such as boroxol ring and tetraborate. The conversion between threefold coordinated boron with the addition of modifier oxides is found in short-range order (SRO) and becomes one of the main factors bringing about the variety of SSs [12]. The ability of boron to exist in threeand four-oxygen coordinate environments and the high strength of covalent B-O bonds enable borate to form stable glasses. Coordination number and connectivity (Number of bridging bonds) usually determine the melting point and Poisson's ratio. Glasses having higher co-ordination number tend to lower the bond strength. A detailed investigation of coordination number is therefore needed to understand the structural properties of glasses. The thermal stability and the lattice vibrations within the glass systems have been related to the measurement of softening and Debye temperature. Boron oxide is one of the best glass formers and its structure consists of a sheet-like arrangement of boron-oxygen triangles connected at all corners to form a continuous network [13]. Physical properties of borate glasses can often be altered by the addition of a network modifier to the basic constituent. The commonly used network modifiers are the alkali and alkaline earth oxides. It was observed that the properties of borate glasses were modified with alkali and alkaline earth oxides. It was observed that the properties of borate glasses modified with alkali oxides showed nonlinear behavior when the alkali oxide was gradually increased [14]. The role of alkali oxide $\mathrm{Na}_{2} \mathrm{O}$ in the $\mathrm{B}_{2} \mathrm{O}_{3}$ network is to modify the host structure through transformation of the structural units of the borate network from $\mathrm{BO}_{3}$ to $\mathrm{BO}_{4}$. The ability of boron atom to exist in three- and four-oxygen coordinated environments and the high strength of the $(\mathrm{B}-\mathrm{O})$ bond enable borates to form stable glasses.

The present work included preparation of two glass systems, namely, (i) $\mathrm{MnO}_{2}-\mathrm{B}_{2} \mathrm{O}_{3}-\mathrm{PbO}$ ( $\mathrm{BML}$ glasses system) and $\mathrm{Na}_{2} \mathrm{CO}_{3}-\mathrm{B}_{2} \mathrm{O}_{3}-\mathrm{P}_{2} \mathrm{O}_{5}$ (BSP glasses system) and its measurement of ultrasonic velocities (both longitudinal $\left(U_{L}\right)$ and shear $\left(U_{S}\right)$ ) and density of the series. From these sample values, the elastic constants such as longitudinal modulus $(L)$, shear modulus $(S)$, bulk modulus $(K)$, Young's modulus $(E)$, Poisson's ratio $(\alpha)$, acoustic impedance $P(Z)$, microhardness $(H)$, Debye temperature $\left(\theta_{D}\right)$, and thermal expansion coefficient $\left(\alpha_{P}\right)$ have been calculated, which give more vital information about the rigidity and structure of glasses. To add more support of our claims over the previous glass samples, we also carried out further studies like spectroscopic $\mathrm{XRD}$ and scanning electron microscope (SEM) to ascertain the validity of the structural elicitation of the prepared glass samples.

\section{Materials and Methods}

2.1. Sample Preparation. The chemicals used in the present research work were analytical reagent (AR) and spectroscopic reagent (SR) grade with minimum assay $99 \%$ being obtained
TABLE 1: Composition of glasses.

\begin{tabular}{lcc}
\hline S. no. & Glass specimen & Composition in mol\% \\
\hline 1 & System-I $\left(\mathrm{B}_{2} \mathrm{O}_{3}-\mathrm{MnO}_{2}\right.$-PbO) \\
2 & BML-1 & $60-10-30$ \\
3 & BML-2 & $62-10-28$ \\
4 & BML-3 & $64-10-26$ \\
5 & BML-4 & $66-10-24$ \\
6 & BML-5 & $68-10-22$ \\
\hline \multicolumn{3}{c}{ BML-6 } \\
\hline 1 & System-II $\left(\mathrm{B}_{2} \mathrm{O}_{3}-\mathrm{Na}_{2} \mathrm{CO}_{3}-\mathrm{P}_{2} \mathrm{O}_{5}\right)$ \\
2 & BSP-1 & $70-10-20$ \\
3 & BSP-2 & $50-25-25$ \\
4 & BSP-3 & $54-25-23$ \\
5 & BSP-4 & $56-25-19$ \\
6 & BSP-5 & $58-25-17$ \\
\hline
\end{tabular}

from Sd Fine Fhemicals, India, and E-Merck, Germany. The composition in mol\% of (increase of $\mathrm{B}_{2} \mathrm{O}_{3}$ and decrease of $\mathrm{PbO} / \mathrm{P}_{2} \mathrm{O}_{5}$ contents) glass specimen is listed in Table 1 . The required amounts (approximately $20 \mathrm{~g}$ ) in $\mathrm{mol} \%$ of different chemicals in powder form were weighed using single pan digital balance (Model SHIMADZU AX 200) having an accuracy of $0.0001 \mathrm{~g}$.

The homogenisation of the appropriate mixture of the component of chemicals was effected by repeating grinding using a pestle and mortar. The temperature controlled muffle furnace was gradually raised to a higher temperature at the rate of $100 \mathrm{~K}$ per hour and a glass structure was noticed for BML glass system at $1060 \mathrm{~K}$ and for BSP glass system $1080 \mathrm{~K}$ and eventually the molten glass melt was immediately poured on a heavy copper molding block having the dimension of $12 \mathrm{~mm}$ diameter and $6 \mathrm{~mm}$ length kept at room temperature. Then the glass samples were annealed at $400 \mathrm{~K}$ for two hours to avoid the mechanical strains developed during the quenching process. The two opposite faces of glass were highly polished to ensure a good parallelism. All glasses are cleaned with acetone to remove the presence of any foreign particles. The samples are prepared chemically stable and nonhygroscopic and such glass samples as system-I (BML) and system-II (BSP) are reported in plate- 1 and plate- 2 .

\subsection{Measurement of Ultrasonic Velocities in Glass Samples.} The ultrasonic longitudinal and shear velocities of the glass specimen were determined by using the pulse-echo overlapping methods at room temperature by making use of $5 \mathrm{MHz} \mathrm{X}$-cut and Y-cut transducers. These transducers act as both transmitters and receivers of the ultrasonic pulse. The transducers were brought into contact with each of the twelve samples by means of a couplant, in order to ensure that there was no air void between the transducer and the specimen.

By applying constant pressure on the probe the echo waveforms were obtained on the display unit and stored in the memory. Figures 2(a) and 2(b) show one of such echo waveforms obtained for longitudinal and shear waves (for BML and BSP systems). 
TABLE 2: Values of density $(\rho)$, longitudinal velocity $\left(U_{L}\right)$, shear velocity $\left(U_{S}\right)$, and elastic moduli of BML and BSP glass systems.

\begin{tabular}{|c|c|c|c|c|c|c|c|}
\hline \multirow[b]{2}{*}{$\begin{array}{l}\text { Name of } \\
\text { the glass } \\
\text { samples }\end{array}$} & \multirow[b]{2}{*}{$\begin{array}{c}\text { Density } \\
\rho \\
\left(\mathrm{Kg} / \mathrm{m}^{3}\right)\end{array}$} & \multicolumn{2}{|c|}{ Ultrasonic velocity (m/s) } & \multicolumn{4}{|c|}{ Elastic moduli } \\
\hline & & $\begin{array}{l}\text { Longitudinal } \\
\text { velocity } \\
\left(U_{L}\right)\end{array}$ & $\begin{array}{c}\text { Shear } \\
\text { velocity } \\
\left(U_{S}\right)\end{array}$ & $\begin{array}{l}\text { Longitudinal } \\
\text { moduli }(L) \\
\times 10^{-9} \mathrm{Nm}^{-2}\end{array}$ & $\begin{array}{c}\text { Shear } \\
\text { moduli }(G) \\
\times 10^{-9} \mathrm{Nm}^{-2}\end{array}$ & $\begin{array}{l}\text { Bulk moduli } \\
\qquad(K) \\
\times 10^{-9} \mathrm{Nm}^{-2}\end{array}$ & $\begin{array}{c}\text { Young's } \\
\text { moduli }(E) \\
\times 10^{-9} \mathrm{Nm}^{-2} \\
\end{array}$ \\
\hline \multicolumn{8}{|c|}{ System-I BML glass systems $\left(\mathrm{B}_{2} \mathrm{O}_{3}-\mathrm{MnO}_{2}-\mathrm{PbO}\right)$} \\
\hline BML-1 & 1304.19 & 4073.34 & 2463.94 & 21.63 & 7.91 & 11.08 & 19.17 \\
\hline BML-2 & 1324.64 & 4177.83 & 2472.42 & 23.12 & 8.08 & 12.32 & 19.92 \\
\hline BML-3 & 1353.70 & 4403.66 & 2533.10 & 26.25 & 8.68 & 14.66 & 21.76 \\
\hline BML-4 & 1359.31 & 4526.08 & 2610.90 & 27.84 & 9.27 & 15.49 & 23.17 \\
\hline BML-5 & 1372.54 & 4550.28 & 2661.44 & 28.42 & 9.72 & 15.55 & 24.44 \\
\hline BML-6 & 1384.01 & 4615.91 & 2693.84 & 29.48 & 10.00 & 16.12 & 25.35 \\
\hline \multicolumn{8}{|c|}{ System-II BSP glass systems $\left(\mathrm{B}_{2} \mathrm{O}_{3}-\mathrm{Na}_{2} \mathrm{CO}_{3}-\mathrm{P}_{2} \mathrm{O}_{5}\right)$} \\
\hline BSP-1 & 1707.92 & 5145.35 & 2875.35 & 45.22 & 14.1 & 26.38 & 34.25 \\
\hline BSP-2 & 1743.67 & 5256.24 & 3055.06 & 48.17 & 16.2 & 26.47 & 40.52 \\
\hline BSP-3 & 1756.72 & 5291.56 & 3153.57 & 49.19 & 17.4 & 25.89 & 42.76 \\
\hline BSP-4 & 1762.19 & 5379.13 & 3186.69 & 50.98 & 17.7 & 27.62 & 43.39 \\
\hline BSP-5 & 1779.83 & 5631.24 & 3222.86 & 56.44 & 18.4 & 31.79 & 46.43 \\
\hline BSP-6 & 1792.60 & 6034.69 & 3296.34 & 65.28 & 1.95 & 39.31 & 50.13 \\
\hline
\end{tabular}

2.3. Density of Glass Samples. The density of the glass samples was measured using relative measurement technique. Benzene was used as a buoyant liquid. The glass samples were weighed both in air and after immersing in benzene at $303 \mathrm{~K}$. The weight of the glass samples was measured in a single pan with an accuracy of $0.0001 \mathrm{~g}$. The density was calculated using the formula

$$
\rho=\rho_{B} \frac{W_{1}}{W_{1}-W_{2}},
$$

where $W_{1}$ and $W_{2}$ are the weights of the glass samples in air and in benzene and $\rho_{B}$ is the density of the benzene at $303 \mathrm{~K}$.

\section{Result and Discussion}

3.1. Ultrasonic Study. The experimental values of density and ultrasonic velocity (both longitudinal $\left(U_{L}\right)$ and shear $\left(U_{S}\right)$ ) of the different glass specimens with respect to change in $\mathrm{mol} \%$ of $\mathrm{PbO}$ and $\mathrm{P}_{2} \mathrm{O}_{5}$ are listed in Table 2. The calculated elastic moduli such as longitudinal modulus $(L)$, shear modulus $(G)$, bulk modulus $(K)$, and Young's modulus $(E)$ are reported in Table 2. The perusal of Table 3 shows the value of Poisson's ratio $(\alpha)$, acoustic impedance $(Z)$, microhardness $(H)$, Debye's temperature $\left(\theta_{D}\right)$, and thermal expansion coefficient $\left(\alpha_{P}\right)$ for the two glass systems (BML and BSP). Figure 3 shows the variation of Debye temperature for the BML glasses with the composition of $\mathrm{PbO}(\mathrm{mol} \%)$. In a similar manner, the variation of the previous parameters with the composition of $\mathrm{P}_{2} \mathrm{O}_{5}$ (mol\%) for BSP glasses is depicted in Figure 3.

Density is an effective tool to explore the degree of structural compactness, modification of the geometrical configuration of the glass network, change in coordination, and the variation of the dimension of the interstitial holes [15]. In our present study, the density of glasses (both BML and BSP glass systems) exhibits continuous increases with increase in mol\% $\mathrm{B}_{2} \mathrm{O}_{3}$. From Table 2, one can notice the monotonic increase of density with increase of $\mathrm{B}_{2} \mathrm{O}_{3}$ concentration which can be attributed to the structure changes occurring in the coordination of boron glass network. The structure of crystalline as well as amorphous $\mathrm{B}_{2} \mathrm{O}_{3}$ is made up of planar $\left(\mathrm{BO}_{3}\right)$ triangles units as reported by Bray [16]. In amorphous $\mathrm{B}_{2} \mathrm{O}_{3}$, most of these triangles are arranged into boroxol rings in which three oxygen are part of the rings and three oxygen are outside the ring. These rings are randomly interconnected through the loose $\left(\mathrm{BO}_{3}\right)$ units. Due to the addition of $\mathrm{B}_{2} \mathrm{O}_{3}$, the three coordinated triangle boron $\left(\mathrm{BO}_{3}\right)$ units are converted to four coordinated boron tetrahedra $\left(\mathrm{BO}_{4}\right)$ and thus the network dimensionality and connectivity increase. This would lead to efficient packing and compactness in the structure, which will be reflected in increase of density of the glass systems. In the present study, the higher values of density are found in BSP glass systems and hence the magnitudes of density values are in the order BSP glass system > BML glass system.

One can notice from Table 2 that the longitudinal $\left(U_{L}\right)$ and shear velocities $\left(U_{S}\right)$ increase linearly with increase in $\mathrm{mol} \% \mathrm{~B}_{2} \mathrm{O}_{3}$ in both BML and BSP glass systems. It is observed that the rate of increase of $U_{L}$ is greater than that of $U_{S}$. Bahatti and Singh [4] suggested that the addition of $\mathrm{PbO}$ and $\mathrm{P}_{2} \mathrm{O}_{5}$ to $\mathrm{B}_{2} \mathrm{O}_{3}$ changes the structure to a rigid and compact structure due to change in the coordination number of boron from 3 to 4 , which causes increase in ultrasonic velocities. The variation of ultrasonic velocities and elastic moduli can be explained on the basis of the structural consideration of glassy network. From Table 2, the values of longitudinal ultrasonic velocity $\left(U_{L}\right)$ increases from 4073.34 to $4615.91 \mathrm{~ms}^{-1}$ for BML glass and 5145.35 to $6034.69 \mathrm{~ms}^{-1}$ for BSP glass systems. Similarly, shear velocity $\left(U_{S}\right)$ increases from 2463.94 to $2693.84 \mathrm{~ms}^{-1}$ for BML glass and 2875.35 to $3296.34 \mathrm{~ms}^{-1}$ for BSP glass systems on increasing the Borate content. 
TABle 3: Values of Poisson's ratio $(\sigma)$, acoustic impedance $(Z)$, microharness $(H)$, Debye temperature $\left(\theta_{D}\right)$, and thermal expansion coefficient $\left(\alpha_{P}\right)$ of BML and BSP glass systems.

\begin{tabular}{|c|c|c|c|c|c|}
\hline $\begin{array}{l}\text { Name of the } \\
\text { glass samples }\end{array}$ & $\begin{array}{l}\text { Poisson's ratio } \\
(\sigma)\end{array}$ & $\begin{array}{c}\text { Acoustic } \\
\text { impedance } Z \\
\left(\times 10^{7} \mathrm{Kg} \cdot \mathrm{m}^{2} \mathrm{~s}^{-1}\right)\end{array}$ & $\begin{array}{l}\text { Microhardness } H \\
\quad\left(\times 10^{-9} \mathrm{Nm}^{-2}\right)\end{array}$ & $\begin{array}{c}\text { Debye temperature } \\
\theta_{D}(\mathrm{~K})\end{array}$ & $\begin{array}{c}\text { Thermal expansion } \\
\text { coefficient } \\
\alpha_{P}\left(\mathrm{~K}^{-1}\right)\end{array}$ \\
\hline \multicolumn{6}{|c|}{ System-I BML glass systems $\left(\mathrm{B}_{2} \mathrm{O}_{3}-\mathrm{MnO}_{2}-\mathrm{PbO}\right)$} \\
\hline BML-1 & 0.211 & 0.5312 & 2.6390 & 144.92 & 94488.1 \\
\hline BML-2 & 0.230 & 0.5534 & 1.4100 & 146.49 & 96912.4 \\
\hline BML-3 & 0.252 & 0.5961 & 1.4300 & 151.54 & 102151.5 \\
\hline BML-4 & 0.250 & 0.6152 & 1.5370 & 156.37 & 104991.7 \\
\hline BML-5 & 0.257 & 0.6245 & 1.5750 & 159.72 & 105553.1 \\
\hline BML-6 & 0.262 & 0.6388 & 1.5935 & 162.12 & 107075.7 \\
\hline \multicolumn{6}{|c|}{ System-II BSP glass systems $\left(\mathrm{B}_{2} \mathrm{O}_{3}-\mathrm{Na}_{2} \mathrm{CO}_{3}-\mathrm{P}_{2} \mathrm{O}_{5}\right)$} \\
\hline BSP-1 & 0.212 & 0.8782 & 2.7130 & 197.68 & 119358.7 \\
\hline BSP-2 & 0.244 & 0.9165 & 2.9830 & 210.31 & 121931.4 \\
\hline BSP-3 & 0.224 & 0.9295 & 3.0145 & 211.38 & 122750.8 \\
\hline BSP-4 & 0.238 & 0.9479 & 3.0600 & 223.36 & 124782.4 \\
\hline BSP-5 & 0.256 & 1.0022 & 3.0710 & 224.03 & 130631.4 \\
\hline BSP-6 & 0.287 & 1.0817 & 3.1765 & 230.16 & 139991.4 \\
\hline
\end{tabular}

According to Higazy and Bridge [17] the longitudinal strain changes directly with bond stretching force constant. On the other hand, as reported by Reisfeld et al. [18], the shear strain changes with bond bending force constant. The increasing trend of both ultrasonic velocities may be attributed to the increase in rigidity of the glass network.

Glass is considered as an elastic substance and it can be characterized through a modulus of elasticity $[19,20]$. This modulus increases as the lengthening of certain applied stress diminishes. This will be the case: if the glass structure is rigid and therefore contains the fewest possible nonbridging oxygen atoms with increase of $\mathrm{B}_{2} \mathrm{O}_{3}$ content, the structure becomes more rigid and so this leads to the increases in density as well as ultrasonic velocities [21-23]. The increase in velocities is attributed to the increases in rigidity of the glass network $[21,24]$. Addition of $\mathrm{B}_{2} \mathrm{O}_{3}$ with $\mathrm{PbO}$ and $\mathrm{P}_{2} \mathrm{O}_{5}$ increases the elastic moduli such as the longitudinal modulus $(L)$, shear modulus $(G)$, bulk modulus $(K)$, and Young's modulus $(E)$ in both glass (BML and BSP) systems. The elevation of such elastic moduli in both glass systems can be interpreted on the basis of the structural consideration of borate network. Further, the addition of $\mathrm{P}_{2} \mathrm{O}_{5}$ and $\mathrm{PbO}$ with $\mathrm{B}_{2} \mathrm{O}_{3}$ network creates $\left(\mathrm{BO}_{4}\right)$ units and this leads to increase in the network dimensionality and connectivity of the network. The increasing trend of elastic moduli in all two glass systems indicates resistance to deformation and is most probably due to the presence of number of layers of covalent bonds. The continuous increase of Poisson's ratio as well as microhardness in the present study reveals the absence of nonbridging oxygen (NBO) and this causes the formation of glassy network. Rajendran et al. [25] observed that increase in elastic moduli with addition of $\mathrm{B}_{2} \mathrm{O}_{3}$ confirms the rigidity and hence the formation of stronger structural building units in this glassy network.
Poisson's ratio is an effective tool in exploring the degree of cross-link density of the glass network and its magnitude increases the cross-link density, and it is the ratio of transverse and linear strains for a linear stress. According to Bridge et al. [26] glass networks having a connectivity of two (zero crosslink density) have Poisson's ratio of $=0.4$. Glass networks having connectivity of three (one cross-link density) have Poisson's ratio of $=0.3$, while networks having a connectivity of four (two cross-link densities) have Poisson's ratio of = 0.15 . It can be seen from the present study that Poisson's ratio increases from 0.211 to 0.262 for BML glass systems and from 0.212 to 0.287 for BSP glass systems (Figures 1 and 5; Tables 4 and 5). The perusal of Table 3 exhibits the values of Poisson's ratio obtained in this study suggesting that the network of these glasses has two-dimensional structure. The increase in Poisson's ratio with increasing content of $\mathrm{B}_{2} \mathrm{O}_{3}$ is attributed to increase in the average cross-link density of the glass as proposed by Higazy and Bridge [17]. The increasing values of Poisson's ratio are attached to strengthening of network linkage and hardening of the network structure. This has been attributed to the fact that the concentration of bonds resisting a transverse deformation decreases in that order [27].

Microhardness expresses the stress required to eliminate the free volume (deformation of the network) of the glass. The present study of increasing value of microhardness in all the two glass systems studied indicates the increase in rigidity of the glass. The softening point is temperature at which viscous flow changes to plastic flow. It determines the temperature stability of the glass. The higher the value of softening temperature, the greater is the stability of its elastic properties [28]. As seen from Table 3, the values of microhardness increase with $\mathrm{B}_{2} \mathrm{O}_{3}$ content. The increase of microhardness implies an increase in the rigidity of the glass system. The present investigation shows that the BSP 


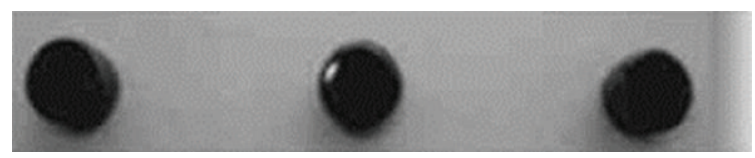

BML-1

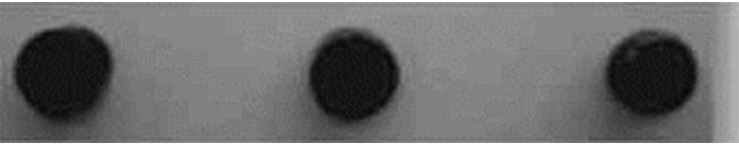

BML-4
BML-5

Plate-1: BML glass specimen

(a)

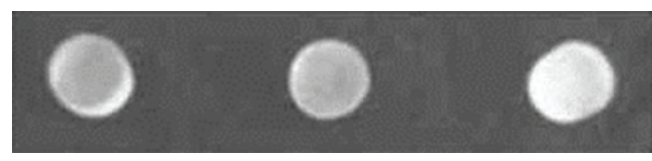

BSP-1

BSP-2

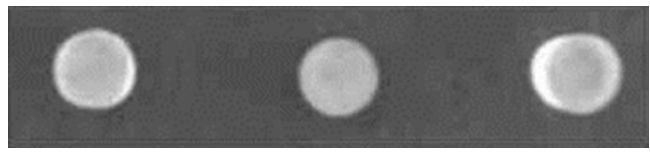

BSP-4

BSP-5

BSP-6

Plate-2: BSP glass specimen

(b)

FIGURE 1: (a) and (b) Photograph for BML and BSP glass systems.
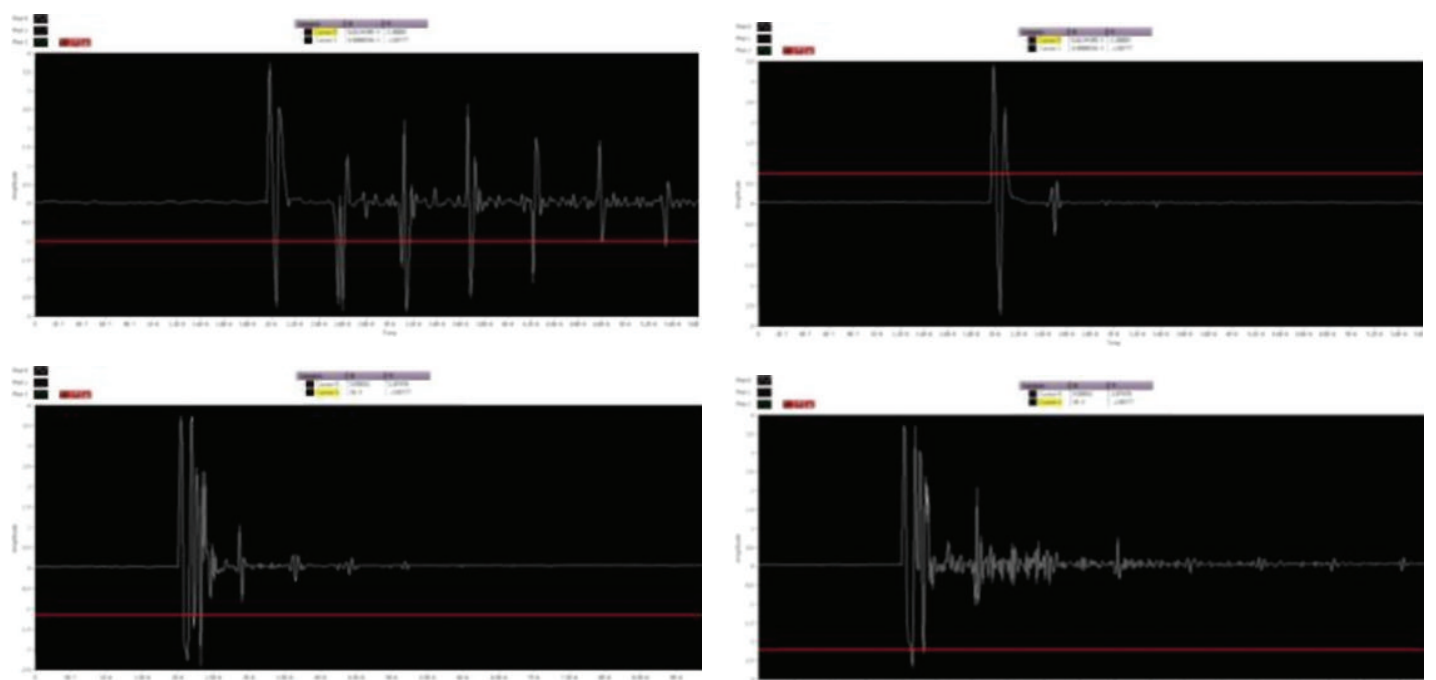

S-I- $U_{L}$ S-I-US

(a)

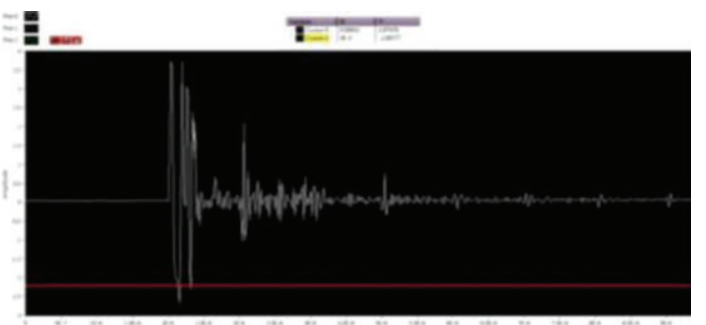

S-II- $U_{L}$

S-II-US

(b)

FIGURE 2: (a) Longitudinal and shear waveforms for BML-I glass system; (b) longitudinal and shear waveforms for BSP-I glass system.

glass systems possess the highest values of microhardness suggesting that BSP glasses are stronger than BML glass systems.

Debye's temperature represents the temperature at which nearly all modes of vibration in a solid are excited and its increasing trend implies an increase in the rigidity of the glass [28]. The perusal of Figure 3 describes the variation of Debye temperature with $\mathrm{B}_{2} \mathrm{O}_{3}$ content.

The gradual increase of Debye's temperature from 144.92 K to $162.12 \mathrm{~K}$ for BML glass systems and from 197.68 to $230.16 \mathrm{~K}$ for BSP glass systems indicates the increase in the rigidity of these glass systems. Such an enhancement of Debye's temperature is attributed to the increase in the number of atoms in the chemical formula of the glass and increase in the ultrasonic velocity [28]. This also further suggests the strengthening in the glass structure which is due to the creation of nonbridging oxygen ions [24]. In our present investigation, the higher values of Debye temperature are reported in BSP glass system. The continuous increase of Debye temperature also suggests the compactness in the structure leading to increase in mean sound velocity [29].

The perusal of Table 3 exhibits the values of acoustic impedance $(Z)$ and the thermal expansion coefficient of the two glass systems studied. The increasing trend of their values for both glass (BML and BSP) systems clearly support this and confirms the strengthening of the glass network in the system. This supports well our earlier conclusions derived from the previous parameters.

3.2. X-Ray Diffraction Study (XRD). X-ray diffraction studies were carried out on each glass sample to confirm the amorphous nature of prepared glasses. An X-ray diffractometer (PW1700: Philips Eindhoven, The New Netherlands) was used with $\mathrm{CuK}$ as a radiation source between $20^{\circ}$ and $80^{\circ}$.

The prepared glass samples were washed gently in doubledistilled water. The washed glass samples were dried at room 
TABle 4: System-I- $\mathrm{B}_{2} \mathrm{O}_{3}-\mathrm{MnO}_{2}-\mathrm{PbO}$ (BML glass system).

\begin{tabular}{lcccccccccccc}
\hline Glass name & \multicolumn{10}{c}{ Peak's positions $\left(\mathrm{cm}^{-1}\right)$} \\
\hline BMP-1 & 540.91 & 641.10 & 805.48 & 1021.55 & 1156.16 & 1194.52 & 1456.13 & 1646.37 & 2854.79 & 2926.03 & 3243.84 & 3426.50 \\
BMP-2 & 541.39 & 697.29 & 876.71 & 1072.71 & 1156.16 & - & 1431.18 & 1645.70 & 2854.79 & 2915.07 & 3221.84 & 3428.01 \\
BMP-3 & 541.84 & 641.10 & - & 1024.96 & 1156.16 & 1189.04 & 1448.39 & 1633.99 & 2854.32 & 2923.98 & 3243.84 & 3430.60 \\
BMP-4 & 541.18 & 646.10 & - & 1021.48 & - & 1194.52 & 1451.49 & 1632.16 & 2854.79 & 2922.24 & 3232.88 & 3415.72 \\
BMP-5 & 542.87 & 645.63 & 821.92 & 1059.75 & - & 1193.22 & 1457.52 & 1637.84 & 2854.79 & 2920.55 & 3227.57 & 3397.91 \\
BMP-6 & 541.36 & - & - & 1062.96 & - & - & 1441.72 & 1631.96 & 2854.19 & 2923.87 & - & 3427.05 \\
\hline
\end{tabular}

TABLE 5: System-II- $\mathrm{B}_{2} \mathrm{O}_{3}-\mathrm{Na}_{2} \mathrm{CO}_{3}-\mathrm{P}_{2} \mathrm{O}_{5}$ (BSL glass system).

\begin{tabular}{|c|c|c|c|c|c|c|}
\hline \multirow{2}{*}{$\begin{array}{l}\text { Glass name } \\
\text { BSP-1 }\end{array}$} & \multicolumn{6}{|c|}{ Peak's positions $\left(\mathrm{cm}^{-1}\right)$} \\
\hline & 685.50 & 1025.04 & 1357.27 & 2849.32 & 2909.59 & 3408.38 \\
\hline BSP-2 & 679.45 & - & 1342.75 & 2854.79 & 2926.03 & 3441.50 \\
\hline BSP-3 & 676.52 & 1059.84 & 1355.92 & 2854.79 & 2923.52 & 3433.21 \\
\hline BSP-4 & 675.91 & 1062.56 & 1350.71 & 2854.79 & 2924.60 & 3431.07 \\
\hline BSP-5 & 686.37 & 1060.61 & 1351.76 & 2849.32 & 2920.55 & 3433.66 \\
\hline BSP-6 & 676.64 & 1028.97 & 1350.85 & 2843.84 & 2915.07 & 3431.14 \\
\hline
\end{tabular}

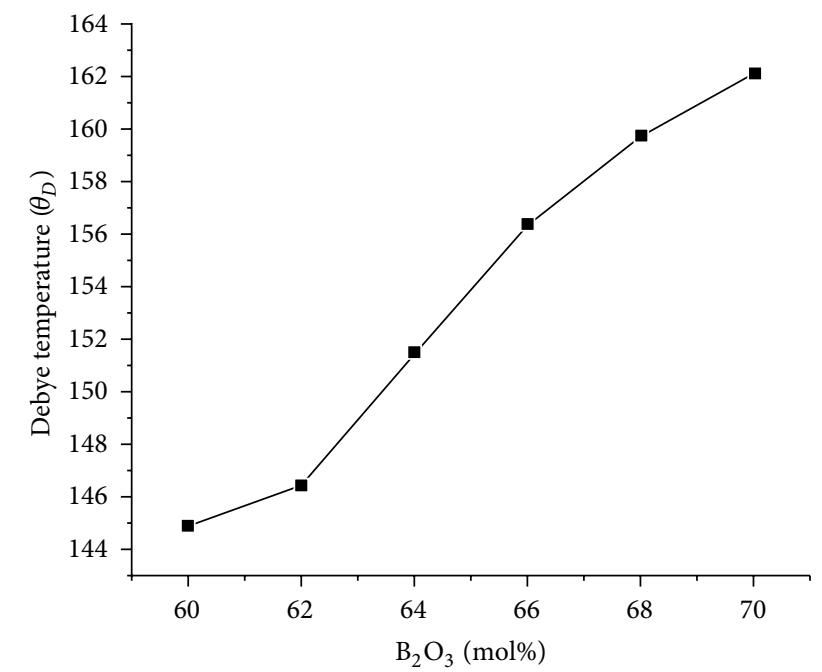

(a)

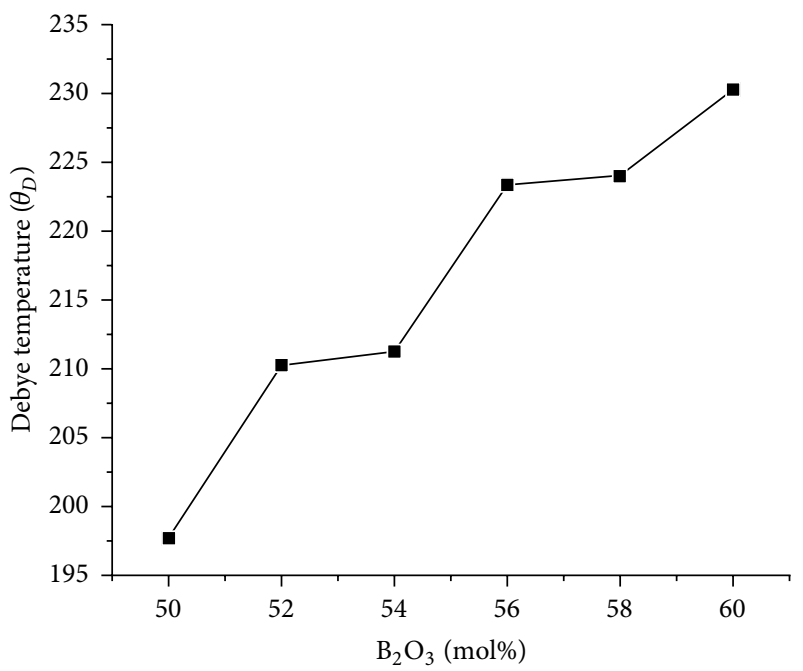

(b)

Figure 3: Debye temperature $\left(\theta_{D}\right)$ with variation of $\mathrm{B}_{2} \mathrm{O}_{3}$ (mol\%) for system I and system II.

temperature, ground, and then used to obtain the XRD patterns as discussed previously. The XRD spectrum shows a number of lines of evidence of unmelted $(W)$ crystalline particles in quarchal glasses. Such XRD spectrums of one of the BML-I and BSP-I glasses systems are shown in Figures 4(a) and 4(b).

3.3. Spectroscopic Study: FTIR Interpretation. The infrared transmission spectra of the glasses are measured at room temperature in the wavenumber range $400-4000 \mathrm{~cm}^{-1}$ by a Fourier transform computerised infrared spectrometer type (Perkin Elmer spectrometer). The prepared glass samples are mixed in the form of fine powder with $\mathrm{KBr}$ in the ratio of $1: 100 \mathrm{mg}$ glass powder: $\mathrm{KBr}$, respectively. The weighed mixtures are then subjected to pressure of $150 \mathrm{~kg} / \mathrm{cm}^{2}$ to produce homogeneous pellets. The infrared transmission measurements are measured immediately after preparing the pellets. Normalized FTIR absorption spectra of $\mathrm{B}_{2} \mathrm{O}_{3}$ $\mathrm{Na}_{2} \mathrm{CO}_{3}-\mathrm{P}_{2} \mathrm{O}_{5}$ and $\mathrm{B}_{2} \mathrm{O}_{3}-\mathrm{PbO}-\mathrm{MnO}_{2}$ are shown in Figures. The goal of vibrational analysis to find vibrational modes is connected with content of glass samples. The observed infrared transmission peak around at $540-541.87 \mathrm{~cm}^{-1}$ is attributed to stretching vibrations of $\mathrm{Pb}-\mathrm{O}[30,31]$. The composition of mole percentage of $\mathrm{PbO}$ is in decreasing trend giving rise to vibrational bands which are slightly shifted to lower wavenumber (Table 6). These vibrational bands do not appeared in the system II because of absence of $\mathrm{PbO}$ content. From FTIR and mole percentage results, the role of $\mathrm{PbO}$ in this glass structures has been explored. Infrared transmission spectra indicate that when composition of $\mathrm{PbO}$ is in the range 
TABLE 6

\begin{tabular}{ll}
\hline Wavenumber $\left(\mathrm{cm}^{-1}\right)$ & Band assignment \\
\hline $540.91-542.87$ & Deformation vibrations of the $\mathrm{Pb}-\mathrm{O}$. \\
$641.10-697.29$ & $\mathrm{~B}-\mathrm{O}-\mathrm{B}$ bonding vibration of $\mathrm{BO}_{3}$ groups and stretching vibration of $\mathrm{MnO}$. \\
$805.48-876.71$ & Stretching vibration of $\mathrm{B}-\mathrm{O}-\mathrm{B}$ lineages in borate network. \\
$1021.48-1072.71$ & $\mathrm{~B}-\mathrm{O}$ bond stretching of the tetrahedral $\mathrm{BO}_{4}$ units. \\
1156.16 & $\mathrm{BO}_{4}$ stretching vibration. \\
$1189.04-1646.37$ & $\mathrm{~B}-\mathrm{O}$ symmetric stretching vibration of $\mathrm{BO}_{3}$ units in metaborate, paraborate, and orthoborate groups. \\
$1025.04-1062.56$ & $\mathrm{PO}_{3}$ symmetric stretching. \\
$1342.75-1357.27$ & Symmetric stretching of $\mathrm{P}-\mathrm{O}-\mathrm{P}$ group. \\
$1631-1646.3$ & $\mathrm{O}-\mathrm{H}$ bending vibrations of water. \\
$2854.32-3415.72$ & $\mathrm{O}-\mathrm{H}$ stretching vibrations of water. \\
\hline
\end{tabular}

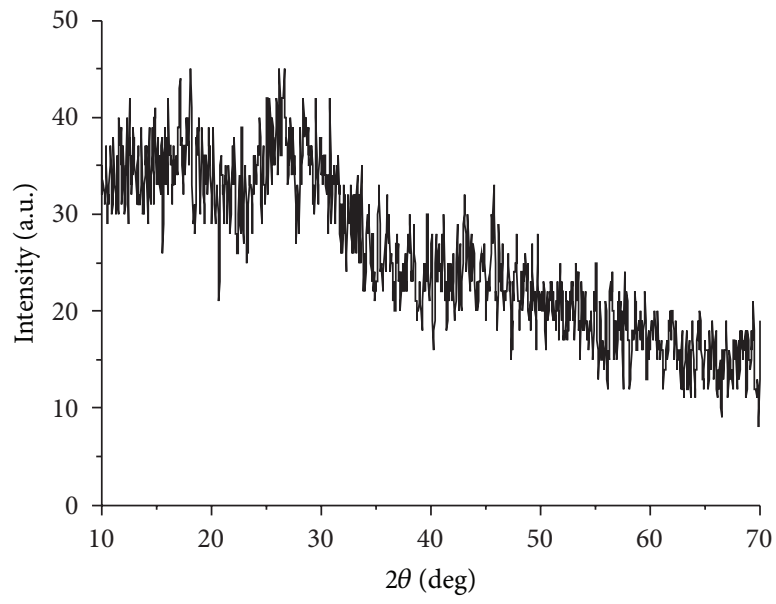

(a)

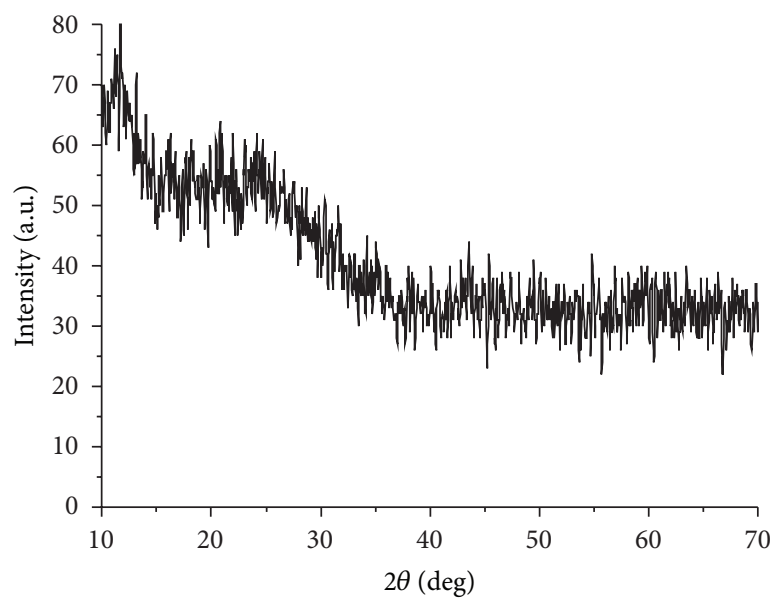

(b)

Figure 4: (a) X-ray diffractogram for BML-I glass system-I; (b) X-ray diffractogram for BSP-I glass system-II.

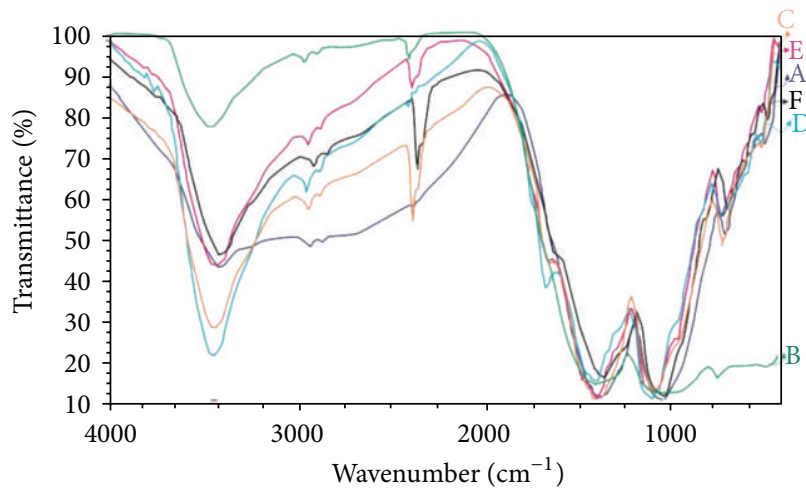

(a)

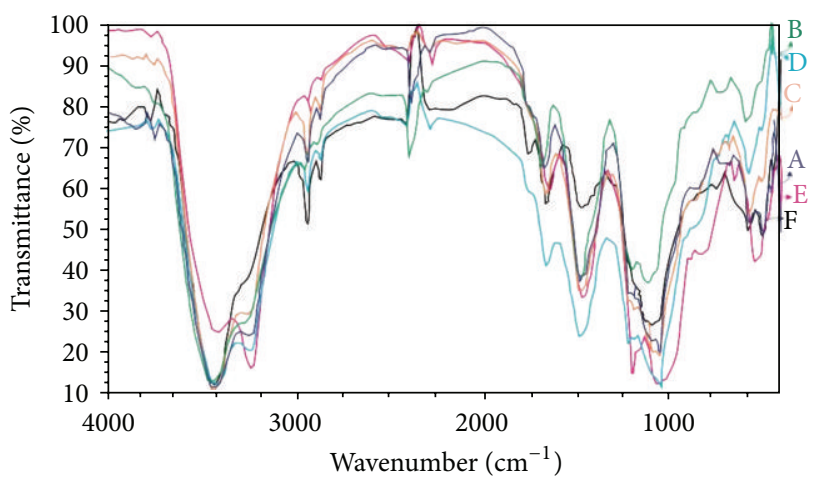

(b)

FIGURE 5: (a) FTIR spectrum for BML glass system; (b) FTIR spectrum for BSP glass system.

$20 \%<x<30 \%$, the $\mathrm{Pb}^{2+}$ ions that are in the borate glass act as a network modifier $[31,32]$. In general, the vibrational modes of the borate network are active mainly in three regions: the first region that lies between 600 and $800 \mathrm{~cm}^{-1}$ is due to bending vibration of various borate segments, the second region that lies between $850-1200 \mathrm{~cm}^{-1}$ is due to stretching vibrations of tetrahedral $\mathrm{BO}_{4}$ units, and the third region that lies between 1200 and $1600 \mathrm{~cm}^{-1}$ is due to stretching vibrations of $\mathrm{B}-\mathrm{O}$ in $\mathrm{BO}_{3}$ triangles. In the present study, the peak observed at around the range $641.1-697.29 \mathrm{~cm}^{-1}$ is assigned as $\mathrm{B}-\mathrm{O}-\mathrm{B}$ bending vibration of borate groups which are composed of $\mathrm{BO}_{4}$ and $\mathrm{BO}_{3}$ units. The stretching normal 

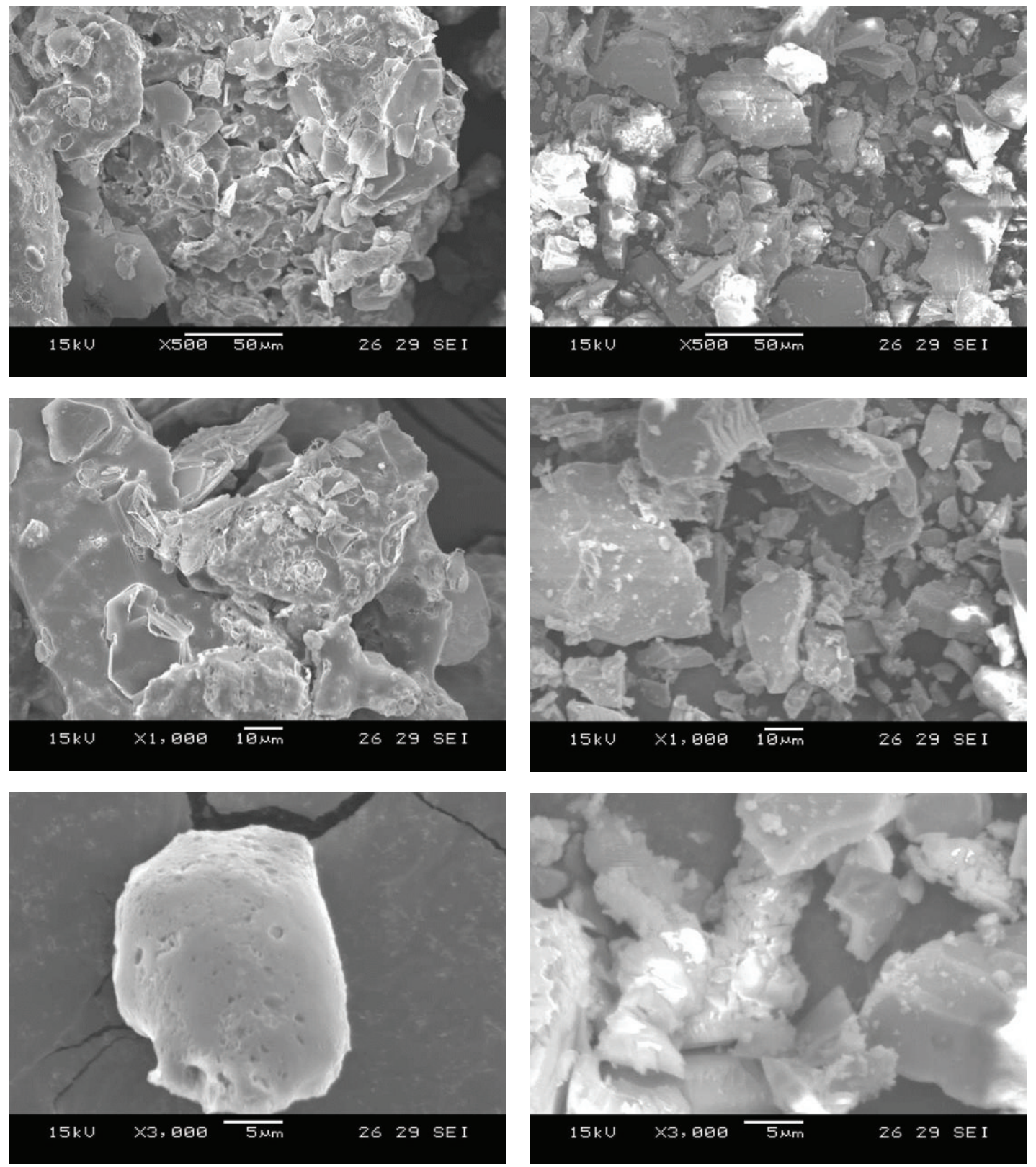

(a)

(b)

FIGURE 6: (a) SEM system-I for BML glass specimen; (b) SEM system-II for BSP glass specimen.

mode of $\mathrm{MnO}_{2}$ is also observed in the previous region; these two vibrational modes overlap with each other [32-34]. The absorption peak identified at the region $805.48-876.71 \mathrm{~cm}^{-1}$ is due to stretching vibration of $\mathrm{BO}_{4}$ groups $[35,36]$. The infrared spectra of the existing structural borate groups and their rearrangement are observed to be slightly affected by the change of glass composition.

In system I, the bands that appeared in the region 1021.48$1072.71 \mathrm{~cm}^{-1}$ are assigned as symmetric stretching vibration of $\mathrm{BO}_{4}$ tetrahedral units $[34,37]$. But in system II, the absorption peaks at around the range $1025.04-1062.56 \mathrm{~cm}^{-1}$ are due to symmetric stretching vibration of $\mathrm{PO}_{3}$ groups.
The previous two stretching vibration modes overlap with each other [38, 39]. The absorption peak identified at $1156.1 \mathrm{~cm}^{-1}$ is due to presence of $\mathrm{BO}_{4}$ stretching vibration. The spectrum of borate glass exhibited vibrational bands at the region $1189.04-1646.37 \mathrm{~cm}^{-1}$ which is due to increasing percentage of $\mathrm{B}_{2} \mathrm{O}_{3}$ in both systems. The $[40,41] \mathrm{B}-\mathrm{O}$ asymmetric stretching vibrations of $\mathrm{BO}_{3}$ units in metaborate, orthoborate, and paraborate appeared at the region 1431.18$1457.52 \mathrm{~cm}^{-1}[42,43]$. The vibrational bands observed at the region $1342.75-1357.27 \mathrm{~cm}^{-1}$ are assigned as antisymmetrical stretching vibrations of $\mathrm{PO}_{2}$ groups. This region may also consist of bands due to $\mathrm{P}=\mathrm{O}$ stretching vibrations. 
This absorption is typically metaphosphate chains. Due to decreasing percentage of $\mathrm{P}_{2} \mathrm{O}_{5}$, in system II, the vibrational bands are slightly shifted to lower wavenumber $[44,45]$. In particular, the atmospheric moisture is easily absorbed by the sample or by the pellet causing the appearance of IR band belonging to $\mathrm{H}_{2} \mathrm{O}$ molecules. The peak at around the region $1631.96-1646.37 \mathrm{~cm}^{-1}$ indicates a change from $\mathrm{BO}_{3}$ triangles to $\mathrm{BO}_{4}$ tetrahedra and this peak may also be assigned to the bending modes of molecular water. The IR bands from $2854.32-3415.72 \mathrm{~cm}^{-1}$ are due to superposition of asymmetric and symmetric stretching vibration of $\mathrm{OH}$. In system I, with the liberation of $\mathrm{CO}_{2}$, the $\mathrm{Na}_{2} \mathrm{CO}_{3}$ is converted into $\mathrm{Na}_{2} \mathrm{O}$ because of its glass transition temperature at $1050^{\circ} \mathrm{C}$. Thus the spectral absorption band of $\mathrm{Na}_{2} \mathrm{CO}_{3}$ is very feeble. IR absorption spectra of the studied samples show various vibrational bands which are characteristics of triangular and tetrahedral borate units together with small bands due to water $\mathrm{OH}$ and $\mathrm{BOH}$. The FTIR studies confirm the presence of various contents of borate network. These vibrational assignments are in good agreement with literature values.

3.4. Scanning Electron Microscopic Study. Scanning electron microscope (SEM) is used in a wide range of fields as a tool for observing surfaces at nanometer level. The main advantage of SEM is its ability to study the heterogeneity of glass composites to visualize various mineral components and their relation in terms of overall micrographic and texture. SEM covers the observation from the fine structures of a surface of specimen to elemental analysis of a microarea without destroying the specimen. The SEM photographs of the samples are given in Figures 6(a) and 6(b). It is obtained that different sized grain particles are distributed. The particle size seems to vary in each micrograph. It consists of density packed grains free from holes.

The particles are angular or spherical in nature. From these figures, it is known that large particles may be monomineralic, but a majority is likely to be composite. Some sphere-like agglomerates found spreading are the glass surfaces, due to deposition of amorphous apatite. This suggests that during glass formation, the presence of clusters composed of fibers is formed. Also, the glass may consist of large particles, aggregates, agglomerates, and clusters, which clearly explain the surface of morphology of glass samples.

\section{Conclusion}

(i) The gradual increase in density with mol\% $\mathrm{B}_{2} \mathrm{O}_{3}$ of the glass specimen indicates the dependence of density on weight of metal atom in the network modifier. The magnitude of the density is in the order BSP > BML.

(ii) The ultrasonic velocities $\left(U_{L}\right.$ and $\left.U_{S}\right)$ of BML and BSP glasses vary linearly with the addition of glass former $\left(\mathrm{B}_{2} \mathrm{O}_{3}\right)$ and the magnitude is in the order BSP $>\mathrm{BML}$.

(iii) The evaluated acoustical, elastic, and mechanical properties of BML and BSP glasses throw light on rigidity and compactness in structural network. (iv) The observed increasing trend of microhardness and Poison's Ratio for both glass systems (BML and BSP) indicates that BSP glass system is stronger than BML system.

(v) The BSP glass possesses higher rigidity and compactness in structural network over the BML.

(vi) The functional groups present in the glass sample have been confirmed by FTIR spectral analysis. The topological aspects of the glass samples are reported from the SEM micrography.

\section{References}

[1] J. Philip, "Temperature dependence of elastic and dielectric properties of $\left(\mathrm{Bi}_{2} \mathrm{O}_{3}\right) 1-\mathrm{X},(\mathrm{CUO}) \mathrm{X}$ oxide glasse," Journal of Materials Science, vol. 35, p. 229, 2000.

[2] F. A. Khalifa, H. A. El Batal, and V. Rajendran, "Behaviour of ultrasonic waves on chromium doped $\mathrm{XPbO}(100 \mathrm{X}) \mathrm{B}_{2} \mathrm{O}_{3}$ glasses," Egyptian Journal of Chemistry, vol. 41, p. 329, 1998.

[3] S. P. Yawale, S. V. Pakade, and C. S. Adganokar, "New type of behavior in ultrasonic velocity and adiabatic compressibility of $\mathrm{Bi}_{2} \mathrm{O}_{3}-\mathrm{B}_{2} \mathrm{O}_{3}$ glass," Acoustica, vol. 81, p. 184, 1995.

[4] S. S. Bahatti and K. J. Singh, "Acoustical and mechanical properties of xMnO.(0.9x) $\mathrm{B}_{2} \mathrm{O}_{3} 0.10 \mathrm{Fe}_{2} \mathrm{O}_{3}$ glass system," Journal of Pure and Applied Ultrasonics, vol. 16, no. 3, p. 78, 1994.

[5] S. V. Pakade and S. P. Yawale, "Ultrasonic velocity and elastic constant measurement in some borate glasses," Journal of Pure and Applied Ultrasonics, vol. 18, p. 74, 1996.

[6] S. J. Jugan and R. Abraham, "Ultrasonic investigation on $\mathrm{Cao}-\mathrm{B}_{2} \mathrm{O}_{3}-\mathrm{Al}_{2} \mathrm{O}_{3}-\mathrm{Na}_{2} \mathrm{O}$ and $\mathrm{Cao}-\mathrm{B}_{2} \mathrm{O}_{3}-\mathrm{Al}_{2} \mathrm{O}_{3}-\mathrm{Fe}_{2} \mathrm{O}_{3}$ glass system," J. Pure Appl.Ultrasonic, vol. 19, p. 32, 1977.

[7] M. Kodamma, "Ultrasonic velocity in sodium borate glasses," Journal of Materials Science, vol. 26, no. 15, pp. 4048-4053, 1991.

[8] S. P. Yawale, S. V. Pakade, and C. S. Adgaonkar, "Ultrasonic velocity and absorption measurement in $\mathrm{xZno}-(90-\mathrm{x}) \mathrm{B}_{2} \mathrm{O}_{3}-$ $10 \mathrm{Bi}_{2} \mathrm{O}_{3}$ glasses," Acoustica, vol. 76, p. 103, 1992.

[9] A. P. Singh, A. Paul, and S. S. Bahatti, "Ultrasonic velocity and absorption measurement in bariumborate glasses and their elastic properties," Indian Journal of Pure and Applied Physics, vol. $483,1990$.

[10] M. S. Gaafar, Y. B. Saddeek, and L. Abd El-Latif, "Ultrasonic studies on alkali borate tungstate glasses," Journal of Physics and Chemistry of Solids, vol. 70, no. 1, pp. 173-179, 2009.

[11] A. Nishara Begum and V. Rajendran, "Structure investigation of $\mathrm{TeO}_{2}-\mathrm{BaO}$ glass employing ultrasonic study," Materials Letters, vol. 61, no. 11-12, pp. 2143-2146, 2007.

[12] T. Yano, N. Kunimine, S. Shibata, and M. Yamane, "Structural investigation of sodium borate glasses and melts by Raman spectroscopy. I. Quantitative evaluation of structural units," Journal of Non-Crystalline Solids, vol. 321, no. 3, pp. 137-146, 2003.

[13] G. D. Chryssikos, M. S. Bitsis, J. A. Kapoidsis, and E. I. Kamitsos, "Vibrational investigation of lithium metaborate-meta aluminate lasses and crystal," Journal of Non-Crystalline Solids, vol. 217, p. 278, 1997.

[14] A. H. Verhoef and H. W. den Hartog, "Infrared spectroscopy of network and cation dynamics in binary and mixed alkali borate glasses," Journal of Non-Crystalline Solids, vol. 182, no. 3, pp. 221234, 1995. 
[15] V. R. Roma, "Elastic properties of the lead containing bismuth tellurite glasses," in Proceedings of the 15th World Conference on Non-Destructive Testing, October 2000.

[16] P. J. Bray, The Structure of Glass, edited by E. Poraikoshits, Consulttant Bureau, New York, NY, USA, 1996.

[17] A. A. Higazy and B. Bridge, "Elastic constants and structure of the vitreous system $\mathrm{Co}_{3} \mathrm{O}_{4}-\mathrm{P}_{2} \mathrm{O}_{5}$," Journal of Non-Crystalline Solids, vol. 72, no. 1, pp. 81-108, 1985.

[18] R. Reisfeld, L. Boehm, Y. Eckstein, and N. Lieblich, "Multiphonon relaxation of rare earth ions in borate, phosphate, germanate and tellurite glasses," Journal of Luminescence, vol. 10, no. 3, pp. 193-204, 1975.

[19] H. B. Senin, H. A. A. Sidek, and G. A. Saunders, "Elastic behavior of terbium metaphosphate glasses under high pressures," Australian Journal of Physics, vol. 47, p. 795, 1994.

[20] H. A. A. Sidek, S. P. Chow, Z. A. Talib, and S. A. Halim, "Formation and electric behavior of lead-magnesium chlorophospate glasses," Turkish Journal of Physics, vol. 28, p. 67, 2004.

[21] Y. B. Saddex, "Ultrasonic study and physical properties of some borate glasses," Materials Chemistry and Physics, vol. 83, p. 222, 2004.

[22] Y. B. Saddex, "Efect of $\mathrm{B}_{2} \mathrm{O}_{3}$ on the structure and properties of tungsten-tellurite Glasses," Philosophical Magazine, vol. 89, p. 41, 2009.

[23] Y. B. Saddex, "Structure and acoustical studies of lead sodium borate glasses," Journal of Alloys and Compounds, vol. 467, p. 14, 2009.

[24] Y. B. Saddex, "Elastic properties of $\mathrm{Gd}_{3}$-doped tellurovanadate glasses using pulse-echo technique," Materials Chemistry and Physics, vol. 91, p. 146, 2005.

[25] V. Rajendran, N. Palanivelu, H. A. El-Batal, F. A. Khalifa, and N. A. Shafi, "Effect of $\mathrm{Al}_{2} \mathrm{O}_{3}$ addition on the acoustical properties of lithium borate glasses," Acoustics Letters, vol. 23, no. 6, pp. 113-121, 1999.

[26] B. Bridge, N. D. Patel, and D. N. Waters, "On the elastic constant and structure of the pure inorganic oxide," Physica Status Solidi A, vol. 77, p. 655, 1983.

[27] K. V. Damodaran and K. J. Rao, "Elastic properties of phosphotungstate glasses," Journal of Materials Science, vol. 24, p. 2380, 1989.

[28] M. A. Sidkey, A. Moneim, and L. Latif, "Ultrasonic studies on ternary $\mathrm{Te}_{2} \mathrm{O}_{2}-\mathrm{V}_{2} \mathrm{O}_{5}-\mathrm{Sn}_{2} \mathrm{O}_{3}$ glasses," Materials Chemistry and Physics, vol. 61, p. 103, 1999.

[29] K. V. Damodaran and K. J. Rao, "Elastic properties of Alkali phosphomolbybate glasses," Journal of the American Ceramic Society, vol. 72, no. 4, pp. 533-539, 1989.

[30] T. Satyanarayana, I. V. Kityk, M. Piasecki et al., "Structural investigations on $\mathrm{PbO}-\mathrm{SB}_{2} \mathrm{O}_{3}-\mathrm{B}_{2} \mathrm{O}_{3}$ : $\mathrm{CoO}$ glass ceramics by means of spectroscopic and dielectric studies," Journal of Physics Condensed Matter, vol. 21, no. 24, Article ID 245104, 2009.

[31] G. P. Singh, P. Kaur, S. Kaur, and D. P. Singh, "Role of $\mathrm{V}_{2} \mathrm{O}_{5}$ in structural properties of $\mathrm{V}_{2} \mathrm{O}_{5}-\mathrm{MnO}_{2}-\mathrm{Pbo}-\mathrm{B}_{2} \mathrm{O}_{3}$ glasses," Materials Physics and Mechanics, vol. 12, p. 58, 2011.

[32] G. P. Singh, P. Kaur, S. Kaur, D. Arora, P. Sing, and D. P. Singh, "Density and FTIR studies of multiple transition metal doped Borate Glass," Materials Physics and Mechanics, vol. 14, p. 31, 2012.

[33] G. D. Khattak and A. Mekki, "Structure and electrical properties of SrO-borovanadate $\left(\mathrm{V}_{2} \mathrm{O}_{5}\right) 0.5(\mathrm{SrO}) 0.5-\mathrm{y}\left(\mathrm{B}_{2} \mathrm{O}_{3}\right) \mathrm{y}$ glassses," Journal of Physics and Chemistry of Solids, vol. 70, no. 10, pp. 1330-1336, 2009.
[34] H. Doweidar and Y. B. Saddeek, "FTIR and ultrasonic investigations on modified bismuth borate glasses," Journal of NonCrystalline Solids, vol. 355, no. 6, pp. 348-354, 2009.

[35] P. Pascuta, R. Lungu, and I. Ardelean, "FTIR and Raman spectroscopic investigation of some strontium-borate glasses doped with iron ions," Journal of Materials Science, vol. 21, no. 6, pp. 548-553, 2010.

[36] I. Ardelean and S. Cora, "FT-IR, Raman and UV-VIS spectroscopic studies of copper doped $\mathrm{Bi}_{2} \mathrm{O}_{3} \cdot \mathrm{B}_{2} \mathrm{O}_{3}$ glass matix," Journal of Materials Science, vol. 19, no. 6, pp. 584-588, 2008.

[37] C. N. Reddy, V. C. V. Gowda, and R. P. S. Chalaradhar, "Elastic properties and structural studies on lead-boro-vanadate glasses," Journal of Non-Crystalline Solids, vol. 354, p. 32, 2008.

[38] A. Shaim, M. Et-Tabirou, L. Montagne, and G. Palavit, "Role of bismuth and titanium in $\mathrm{Na}_{2} \mathrm{O}-\mathrm{Bi}_{2} \mathrm{O}_{3}-\mathrm{TiO}_{2}-\mathrm{P}_{2} \mathrm{O}_{5}$ glasses and a model of structural units," Materials Research Bulletin, vol. 37, no. 15, pp. 2459-2466, 2002.

[39] A. H. Khafagy, "Infrared and ultrasonic investigations of some $\left[\left(\mathrm{MnO}_{2}\right) \mathrm{x}-\left(\mathrm{P}_{2} \mathrm{O}_{5}\right) 100-\mathrm{x}\right] .1 \mathrm{wt} \% \mathrm{Ncl}_{2} \mathrm{O}_{3}$ glasses," Physica Status Solidi A, vol. 186, no. 1, p. 105, 2011.

[40] G. P. Singh, P. Kaur, S. P. Kaur, and D. P. Singh, "Role of $\mathrm{V}_{2} \mathrm{O}_{5}$ in structural properties of $\mathrm{V}_{2} \mathrm{O}_{5}-\mathrm{MnO}_{2}-\mathrm{Pbo}-\mathrm{B}_{2} \mathrm{O}_{3}$ glasses," Materials Physics and Mechanics, vol. 12, pp. 58-63, 2011.

[41] P. Y. Shih, S. W. Yung, and T. S. Chin, "FTIR and XPS studies of $\mathrm{P}_{2} \mathrm{O}_{5}-\mathrm{Na}_{2} \mathrm{O}-\mathrm{CuO}$ glasses," Journal of Non-Crystalline Solids, vol. 244, no. 2, pp. 211-222, 1999.

[42] E. Culea, L. Pop, M. Bosca, V. Dan, P. Pascuta, and S. Rada, "Structural and physical characteristics of $\mathrm{xGd}_{2} \mathrm{O}_{3}(100-$ $\mathrm{x})\left[\mathrm{Bi}_{2} \mathrm{O}_{3} \mathrm{~B}_{2} \mathrm{O}_{3}\right]$ glasses," Journal of Physics, vol. 182, no. 1, Article ID 012062, 2009.

[43] P. Pasuta, M. Bosca, and S. Reda, "FTIR spectro scopic study of $\mathrm{Gd}_{2} \mathrm{O}_{3}-\mathrm{Bi}_{2} \mathrm{O}_{3}-\mathrm{B}_{2} \mathrm{O}_{3}$ glasses," Journal of Optoelectronics and Advanced Materials, vol. 10, pp. 2416-2419, 2008.

[44] G. D. Khattak and A. Mekki, "Structure and electrical properties of SrO-borovanadate $\left(\mathrm{V}_{2} \mathrm{O}_{5}\right) 0.5(\mathrm{SrO}) 0.5-\mathrm{y}\left(\mathrm{B}_{2} \mathrm{O}_{3}\right)$ y glassses," Journal of Physics and Chemistry of Solids, vol. 70, no. 10, pp. 1330-1336, 2009.

[45] D. Souri, "Dsc and FTIR spectra of Tellurite vanadate glasses containg Molebdenum," Middle-East Journal of Science Research, vol. 5, no. 1, p. 44, 2010. 

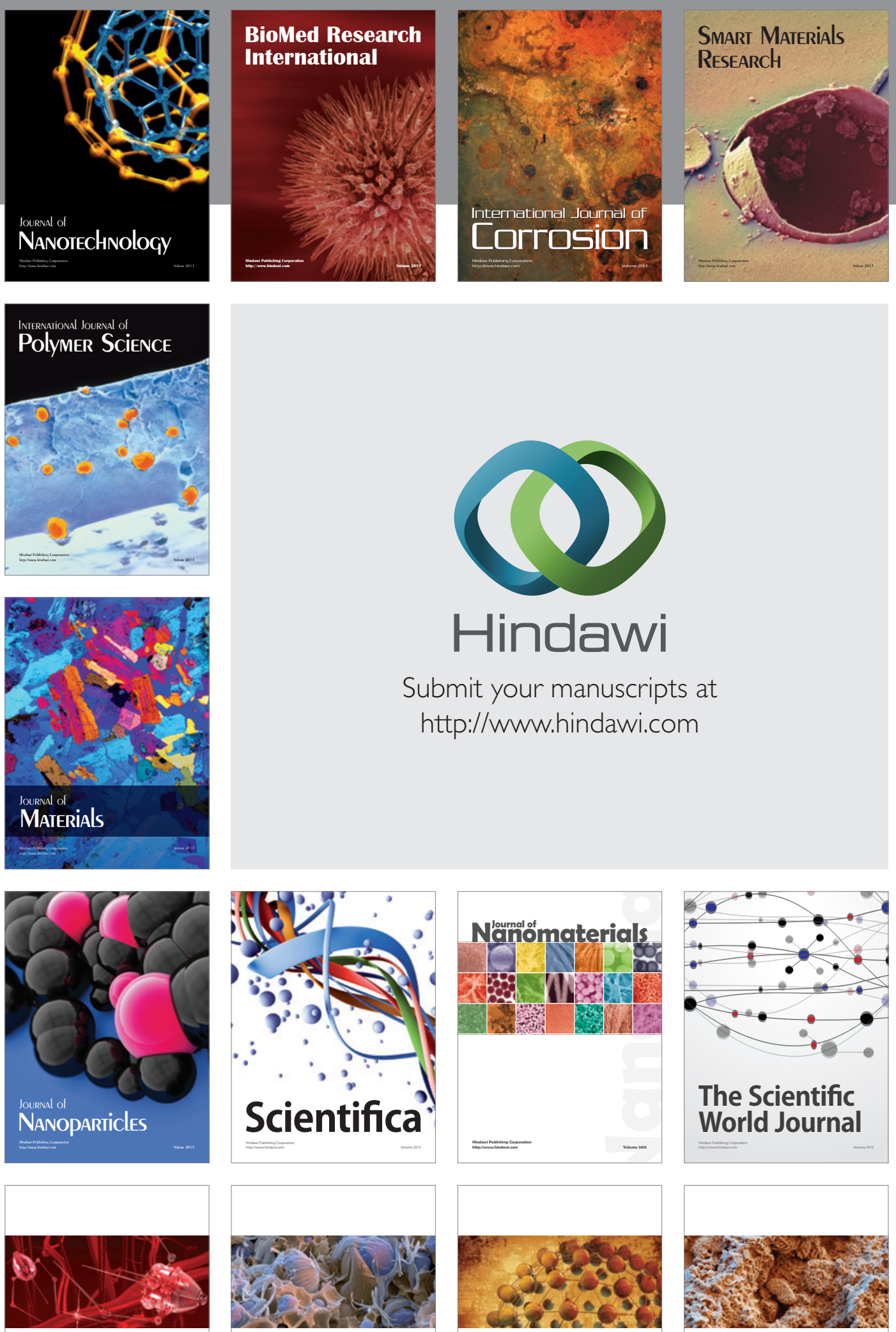

ISRN

Nanotechnology
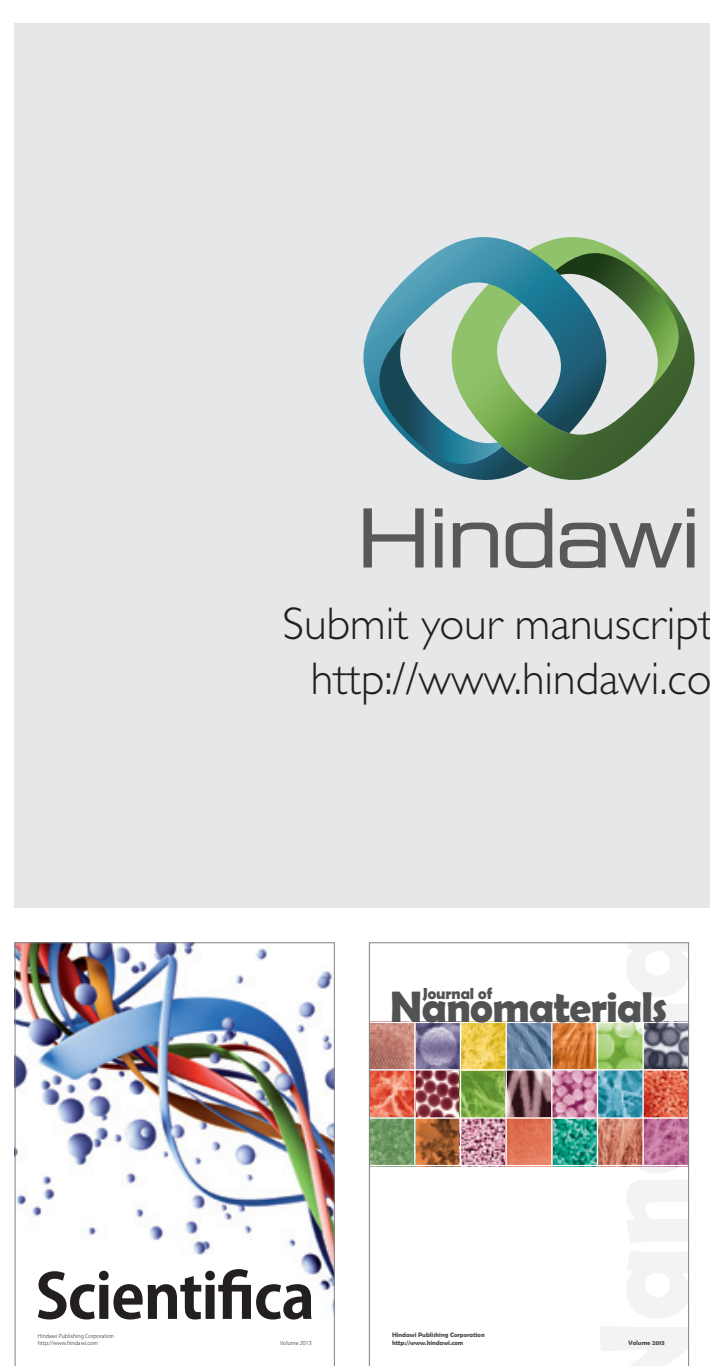

Submit your manuscripts at http://www.hindawi.com
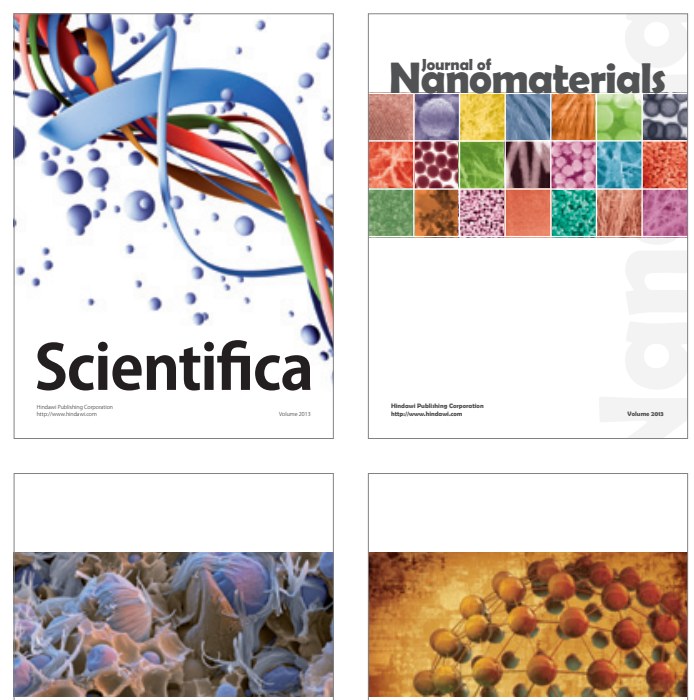

ISRN

Polymer Science

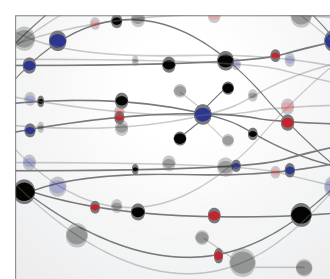

The Scientific World Journal

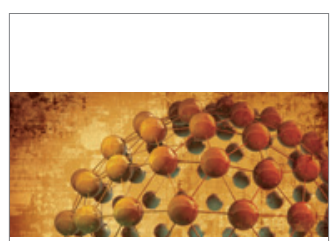

ISRN

Materials Science

\section{World Jounal}

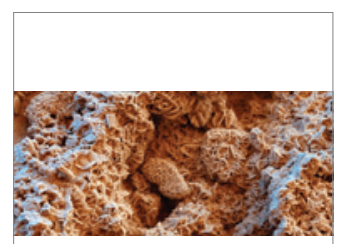

ISRN

Corrosion
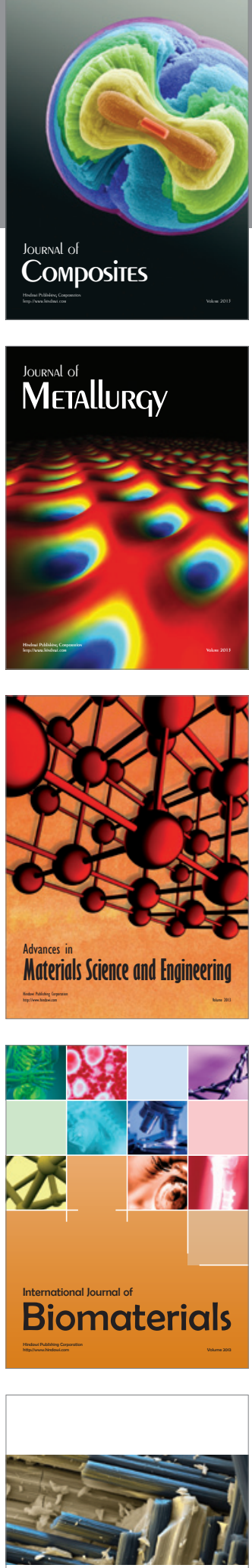

ISRN

Ceramics 